\title{
Avaliação toxicológica: alterações em biomarcadores desencadeadas por exposição de trabalhadores rurais a agrotóxicos
}

\author{
Toxicological evaluation: changes in biomarkers triggered by exposure of rural workers to \\ pesticides
}

Evaluación toxicológica: cambios en los biomarcadores provocados por la exposición de los trabajadores rurales a los plaguicidas

Recebido: 10/01/2021 | Revisado: 11/01/2021 | Aceito: 11/01/2021 | Publicado: 11/01/2021

\author{
Murilo De Jesus Porto \\ ORCID: https://orcid.org/0000-0003-2339-8173 \\ Universidade do Estado da Bahia, Brasil \\ E-mail: murilo.porto@hotmail.com \\ Jaciara Pinheiro de Souza \\ ORCID: https://orcid.org/0000-0002-4056-974X \\ Centro Universitário UniAges, Brasil \\ E-mail: jacipinheirosouza@hotmail.com \\ Emile Ivana Fernandes Santos Costa \\ ORCID: https://orcid.org/0000-0002-6509-1279 \\ Universidade do Estado da Bahia, Brasil \\ E-mail: emilecostaivana@gmail.com \\ Cinara Rejane Viana Oliveira \\ ORCID: https://orcid.org/0000-0002-4835-2481 \\ Universidade do Estado da Bahia, Brasil \\ E-mail: cinara-rejane@ hotmail.com \\ Maria de Fátima Santana de Souza Guerra \\ ORCID: https://orcid.org/0000-0002-2760-8230 \\ Centro Universitário UniAges, Brasil \\ E-mail:marinaide10@gmail.com \\ Ana Mara Borges Araujo \\ ORCID: https://orcid.org/0000-0003-4065-241X \\ Centro Universitário UniAges, Brasil \\ E-mail: anamaraborges_@hotmail.com \\ Jeferson de Menezes Souza \\ ORCID: https://orcid.org/0000-0001-7688-8606 \\ Centro Universitário UniAges, Brasil \\ E-mail: jefssersonn.ms@hotmail.com
}

\begin{abstract}
Resumo
Os agrotóxicos ou pesticidas são considerados substâncias quimícas que agem no meio ambiente, no sentido de controlar diferentes elementos que prejudicam o cultivo das lavouras ou pastagens, geralmente, sendo utilizados por trabalhadores ocupacionais a nível rural no intuito de maior produção e erradicação de doenças e pragas exitentes. Muitos trabalhadores não sabem lidar corretamente com a aplicação, compra, diluição e descarte dos agroquímicos. Dessa maneira, esta pesquisa tem como objetivo discutir as principais alterações em biomarcadores desencadeadas por exposição de trabalhadores rurais a agrotóxicos. Como metodologia o presente estudo trata-se de revisão narrativa, realizada entre os meses de agosto e dezembro de 2020. O levantamento de dados não se pautou para restrição do ano de publicação dos estudos encontrados. As bases de dados utilizadas foram: National Center for Biotechnology Information (PUBMED); Scientific Electronic Library Online (SCIELO); Literatura LatinoAmericana e do Caribe em Ciências da Saúde (LILACS); sites confiáveis; livros. A presente pesquisa mostra que o monitoramento de biomarcadores de exposição a agrotóxicos pode ser útil para verificar o surgimento de disfunções fisiológicas em populações expostas. Ressalta-se que os biomarcadores mais utilizados para a avaliação dos trabalhadores expostos aos agrotóxicos seriam as enzimas acetilcolinesterase eritrocitária (AChE) e butirilcolinesterase (BuChE), assim com o processo de exposição a agrotóxicos desencadea uma série de reações fisiológicas a nível nervoso, diminuindo, principalmente, a ação da enzima acetilcolinesterase, essa que por sua vez é responsável pela quebra do excesso da acetilcolina.
\end{abstract}

Palavras-chave: Avaliação da exposição; Agrotóxicos; Trabalhadores rurais. 


\begin{abstract}
Pesticides or pesticides are considered chemical substances that act in the environment, in order to control different elements that harm the cultivation of crops or pastures, generally being used by occupational workers at rural level in order to increase production and eradicate diseases and pests existing. Many workers do not know how to correctly handle the application, purchase, dilution and disposal of agrochemicals. Thus, this research aims to discuss the main changes in biomarkers triggered by exposure of rural workers to pesticides. As a methodology, this study is a narrative review, carried out between the months of August and December 2020. The data collection was not based on the restriction of the year of publication of the studies found. The databases used were: National Center for Biotechnology Information (PUBMED); Scientific Electronic Library Online (SCIELO); Latin American and Caribbean Literature on Health Sciences (LILACS); trusted sites; books. The present research shows that the monitoring of biomarkers of exposure to pesticides can be useful to verify the appearance of physiological dysfunctions in exposed populations. It is noteworthy that the biomarkers most used for the evaluation of workers exposed to pesticides would be the enzymes acetylcholinesterase erythrocyte (AChE) and butyrylcholinesterase (BuChE), as well as the process of exposure to pesticides triggers a series of physiological reactions at the nervous level, decreasing, mainly, the action of the enzyme acetylcholinesterase, which in turn is responsible for the breakdown of excess acetylcholine.
\end{abstract}

Keywords: Exposure assessment; Pesticides; Rural workers.

\title{
Resumen
}

Los plaguicidas o plaguicidas se consideran sustancias químicas que actúan en el medio ambiente, con el fin de controlar diferentes elementos que dañan el cultivo de cultivos o pastos, siendo generalmente utilizados por trabajadores ocupacionales a nivel rural con el fin de incrementar la producción y erradicar enfermedades y plagas. existente. Muchos trabajadores no saben cómo manejar correctamente la aplicación, compra, dilución y eliminación de agroquímicos. Así, esta investigación tiene como objetivo discutir los principales cambios en los biomarcadores provocados por la exposición de los trabajadores rurales a los plaguicidas. Como metodología, el presente estudio es una revisión narrativa, realizada entre los meses de agosto y diciembre de 2020. La recolección de datos no se basó en la restricción del año de publicación de los estudios encontrados. Las bases de datos utilizadas fueron: Centro Nacional de Información Biotecnológica (PUBMED); Biblioteca Electrónica Científica en Línea (SCIELO); Literatura Latinoamericana y del Caribe en Ciencias de la Salud (LILACS); sitios de confianza; libros. La presente investigación muestra que el seguimiento de biomarcadores de exposición a plaguicidas puede ser útil para verificar la aparición de disfunciones fisiológicas en poblaciones expuestas. Es de destacar que los biomarcadores más utilizados para la evaluación de trabajadores expuestos a plaguicidas serían las enzimas acetilcolinesterasa eritrocito (AChE) y butirilcolinesterasa $(\mathrm{BuChE})$, así como el proceso de exposición a plaguicidas desencadena una serie de reacciones fisiológicas a nivel nervioso, decrecientes, principalmente, la acción de la enzima acetilcolinesterasa, que a su vez es responsable de la descomposición del exceso de acetilcolina.

Palabras clave: Evaluación de la exposición; Plaguicidas; Trabajadores rurales.

\section{Introdução}

Com o crescimento populacional, houve uma maior demanda por alimentos, despertando maiores interesses em investimentos na produção agricultora. A indústria química trouxe consigo a justificativa para o uso de substâncias químicas, favorecendo o desenvolvimento e controle de organismos dos meios agrícolas que poderiam afetar a produtividade (Almeida et al., 2017).

Para Murussi e colaboradores (2014), as práticas e utilização de agrotóxicos e/ou pesticidas no ramo da agricultura, muitas vezes, acabam gerando efeitos adversos sobre o ambiente e, principalmente, sobre os seres humanos, já que o seu uso insdicriminado pode fornecer uma série de episódios de intoxicações que são classificadas como agudas ou crônicas.

$\mathrm{O}$ uso indiscriminado de agrotóxicos gerado pelo mercado em expansão, vem causando um aumento no número de intoxicações por estas substâncias. Dentre as intoxicações exógenas notificadas no ano de 2014 pelo Sistema de Informação de Agravos de Notificação (SINAN), as intoxicações agudas por agrotóxicos ocupam a segunda posição. Na região sul do país, a maioria dos casos de intoxicação causadas por estas substâncias ocorre na área rural, principalmente, no contexto ocupacional, em trabalhadores que aplicam inseticidas na lavoura, ou pela ingestão destes produtos por acidente (Queiroz et al., 2019). 
A utilização dos agrotóxicos tornou-se essencial para o ambiente agrícola favorecendo o aumento da produtividade, contudo, a manipulação dessas substâncias químicas pode gerar a exposição ocupacional dos trabalhadores, principalmente, do meio rural, pois são os que estão ligados diretamente com o manuseio de pesticidas (Horn, 2016).

Vale ressaltar que há distintas classes de produtos químicos utilizados no cultivo da agricultura, porém os que chamam mais a atenção são os organofosforados e carbamatos pelo alto potencial de inibição das enzimas acetilcolinesterases (AChE) gerando um conjunto de respostas fisiopatológicas em distintas regiões do corpo humano (Horn, 2016).

Nos países em desenvolvimento, pesticidas inibidores de colinesterase (das classes dos organofosfatos e carbamatos), são considerados os principais responsáveis pelo envenenamento de humanos causados por pesticidas. A exposição aguda a organofosfatos e carbamatos tem sido bem documentada, pois inibem a acetilcolinesterase neuronal (AChE) (Nerilo et al., 2014).

Desta forma, estudos de populações expostas usam geralmente biomarcadores de exposição ou efeito de susceptibilidade. Por exemplo, quantidades vestigiais do composto de origem no sangue, ou os seus metabólitos na urina, são utilizados como biomarcadores de exposição.Já para a inibição da atividade catalítica de eritrócitos AChE é frequentemente utilizado como um biomarcador de efeitos agudos, sendo considerado o melhor indicador para extrapolar efeitos inibitórios nas sinapses no sistema nervoso. No entanto, a butirilcolinesterase (BChE) (enzima do plasma sintetizado no fígado com propriedades catalíticas semelhantes a AChE), é também habitualmente utilizada para determinar a exposição aguda em programas de biomonitoramento. As razões para medir a BChE em vez da atividade da $\mathrm{AChE}$ incluem o seu maior grau de reprodutibilidade entre laboratórios abrangendo marcadores renais, hepáticos e inflamatórios (Santana, 2018).

Dessarte, a justificativa para a realização do estudo, enfatiza a precisão e prática de normas voltadas para as devidas ações de vigilância em saúde para os trabalhadores com exposição a agrotóxicos, submergindo os distintos enfoques de setores da saúde que lidam com esse artifício de cunho epidemiológico, ambiental, saúde do trabalhador e sanitário. Dessa maneira, essa pesquisa tem como objetivo discutir as principais alterações em biomarcadores desencadeadas por exposição de trabalhadores rurais a agrotóxicos

\section{Metodologia}

O presente estudo trata-se de revisão narrativa, com característica quantitativa, realizada entre os meses de agosto e dezembro de 2020. O levantamento dos dados não se pautou para restrição do ano de publicação dos estudos encontrados. As bases de dados utilizadas foram: National Center for Biotechnology Information (PUBMED); Scientific Electronic Library Online (SCIELO); Literatura Latino-Americana e do Caribe em Ciências da Saúde (LILACS); sites confiáveis; livros.

Esse estudo foi realizado a partir de dados registrados em fontes secundárias coletados por meio de levantamento bibliográfico, o que caracteriza a pesquisa bibliográfica que para (Marconi \& Lakatos, 2010, p.25):

A revisão bibliográfica é indispensável para a delimitação do problema em um projeto de pesquisa e para obter uma ideia precisa sobre o estado atual dos conhecimentos sobre um tema, sobre suas lacunas e sobre a contribuição da investigação para o para o desenvolvimento do conhecimento.

Assim, a presente pesquisa possui característica descritiva, apresentando descrição das propriedades de uma determinada população ativa em um dado momento da pesquisa, conforme Gil (2012), tendo por desígnio mostrar as opiniões e créditos. Submerge o uso de metodologias unificadas de coleta de dados: questionário e observação sistemática. Admite, em geral, a configuração de classificação dos devidos dados. 
A respeito da questão bibliográfica a nível narrativa, se analisa um contexto através dos objetivos, justificativa e problemática da pesquisa que envolvem vários níveis de conhecimentos para englobar aspectos essenciais do conhecimento e discutir, com distintos autores, a devida pesquisa, mostrando as considerações finais do projeto (Koche, 2004).

Como inclusão dos artigos, foram analisados os Descritores em Saúde: educação continuada em saúde para enfermeiros. Os presentes descritores escolhidos foram ajustados, de acordo com a base de dados. Como critérios de inclusão: artigos dos últimos 10 anos; publicados no Brasil, periódicos com descritores em toxicologia de agrotóxicos e efeitos tóxicos de agrotóxicos a nível hematológico. Já os critérios de exclusão: periódicos inferiores ao ano de 2010; publicações incompletas; pesquisas que cobrassem pelo acesso.

\section{Resultados Discussão}

\section{Uso dos agrotóxicos}

O conceito de agrotóxicos está determinada pela Lei Federal $n^{\circ} 7.802$, de 11 de junho de 1989, e está proposto ainda dentro do decreto $\mathrm{n}^{\circ} 4.074$, de 04 de Janeiro de 2002 como: produtos e agentes de processos físicos, químicos ou biológicos, anunciados ao uso nos domínios de cultivo, relacionado as questões de produtos agrícolas, como proteção de florestas, ou plantadas, livres de problemas que gera danos ao ecossistemas (Brasil, 2006 \& Alves, 2017). Os agrotóxicos são substâncias químicas, com características biocida, no qual é empregado para diversas pragas e distintas doenças que agridem o ambiente agrícola. Vale ressaltar que apesar dos seus malefícios há o uso indiscriminado em vários países, e o Brasil entra nesse ranking sendo o maior consumidor de agrotóxicos (Bocnher, 2015).

Desde de 2019, foram aprovados no Brasil mais de 475 novos tipos de pesticidas, valor muito superior a tendência de crescimento dos anos anteriores (Braga et al., 2020). Uma das principais justificativas para o aumento no ritmo de aprovação dos agrotóxicos foi justamente a diminuição da burocracia envolvida no licenciamento de novos produtos comerciais (Vasconcelos, 2018). O uso de combinados organoclorados, entre eles o DDT (Dicloro-Difenil-Tricloroetano), principiou a acontecer também nesse mesmo momento. Sendo assim, a fração de agroquímicos do negócio interno proporcionou faturamento em elevação, quando então o Brasil mostrou o comando no consumo mundial de substâncias químicas agrícolas, posição antes ocupada pelos Estados Unidos (Linhares, 2014).

O Brasil está entre os principais fornecedores de alimentos no mundo, sendo o maior exportador de suco de laranja (78,6\%), café $(26,8 \%)$, açúcar $(45,7 \%)$, soja $(42,9 \%)$ e milho $(19,4 \%)$, e também está entre os principais produtores e exportadores de carne bovina, aves, carne de porco, cereais, arroz, floresta produtos, frutas e outros vegetais (Araújo et al., 2015). Sendo assim, a utilização exacerbada de agrotóxicos pode impactar no fornecimento de alimentos em todo o mundo (Braga et al., 2020).

Para além da utilização de agrotóxicos na produção de alimentos, encontra-se a intoxicação de trabalhadores pelo uso indevido dos agrotóxicos. Segundo os dados publicados pela Organização Internacional do Trabalho (OIT)/Organização Mundial da Saúde (OMS), aproximadamente 70 mil trabalhadores de distintos países foram a óbito por consequência de intoxicações agudas e crônicas por uso indevido de agrotóxicos (Faria et al., 2007; Taveira \& Albuquerque, 2018).

O processo de intoxicação por uso de agrotóxicos pode acontecer em distintos mecanismos, sendo eles por via digestiva, respiratória, dérmica e/ou por contato ocular, acarretando conjuntos de sintomas com características agudas, subagudos ou crônicos. Entre os grupos mais afetados pelos danos determinados pelas substâncias químicas agrícolas, encontra- se os trabalhadores da agricultura e da pecuária, que são vulneráveis aos agrotóxicos desde o preparo, manipulação até armazenamento dos recipientes após o uso (Taveira \& Albuquerque, 2018). 
A intoxicação por substâncias químicas utilizados na agricultura é dividida em: intoxicação aguda e crônica. A intoxicação aguda manifesta-se geralmente de cunho mais leve, moderada chegando até mesmo aos casos mais graves. A intoxicação aguda leve proporciona um quadro de sinais de irritação em região cutânea- mucosa, cefaleia, dermatite, tontura leve e em alguns casos náuseas. O processo de intoxicação aguda pode surgir também com quadros de êmese associado a náuseas, cefaleia muito intensa, cólicas abdominais, fraqueza em todo o corpo, dispneia, parestesia e sudorese intensa. No caso de intoxicação aguda grave, pode gerar hipotensão arterial, alterações no ritmo cardíacos, miose, insuficiência respiratória, convulsões, edema de pulmão, podendo surgir casos de óbitos (Melo \& Gonçalves, 2014). Já nos casos de intoxicação crônica, o aparecimento dos sintomas acontece mais tardiamente, sendo característico a exposição prolongada de meses ou anos, ocasionando danos irreversíveis, surgimento de paralisias e neoplasias (Paraná, 2018).

A exposição aos agrotóxicos pode também causar alterações celulares, sendo que essas alterações consequentemente podem estar associadas a diferentes tipos de cânceres, como por exemplo: câncer no cérebro, linfoma não-Hodgki, melanoma cutâneo, câncer no sistema digestivo, sistemas genitais masculino e feminino, sistema urinário, sistema respiratório (Wilhelm et al., 2015, Da Silva et al., 2012, Miranda et al., 2014, Buccolini et al., 2013, Costa et al., 2017, Fortes et al., 2016, Segatto et al., 2015 \& Da Silva et al., 2016).

Atualmente, configura-se de grande importância a monitorização periódica das condições de exposição a agrotóxicos de populações de risco. Porém, diversos são os desafios enfrentados pelos órgãos competentes podendo-se citar: o grande número de substâncias registradas e autorizadas no país, contrabando de ativos ilegais, falta de registro sistemático de atividades pelos trabalhadores rurais (como dose, frequência, tempo de exposição e épocas de aplicação dos agrotóxicos), utilização de misturas de ativos, principalmente nas pequenas propriedades, dificuldades na identificação de exposições crônicas (sinais e sintomas inespecíficos) e as sub-notificações pelos profissionais da Saúde (Korbes et al., 2010).

\section{Biomarcadores sanguíneos}

Os biomarcadores ou marcadores biológicos humanos (denominação mais comum) são combinados imunoativos achados no corpo mais facilmente na corrente sanguínea, urina, fluídos e tecidos corporais, podendo sugerir função normal ou um episódio de instalação patológica (Correia et al., 2018).

No processo fisiopatológico da intoxicação a agrotóxicos, o SNC é um dos mais atingidos pela exposição prolongada, sendo afetado as constituintes de neurônios (célula do sistema nervoso), alterando os impulsos elétricos e químicos. Os impulsos elétricos são denominados de sinapse que é passado de um neurônio para outro até chegar no alvo para obter a resposta, já os impulsos químicos são denominados de neurotransmissores ou substância transmissora promovendo uma excitação, inibição ou ainda modificação de algo a nível celular (Guyton \& Hall, 2017).

Existem 40 tipos de substâncias neurotransmissoras, as mais relatantes são acetilcolina, norapinefrina, epinefrina, histamina, ácido gama-aminobutirico (GABA), glicina, serotonina e glutamato (Guyton \& Hall, 2017).

A acetilcolina age nas junções musculares esqueléticas induzindo a contração do músculo, age também na sinapse entre o nervo vago e as fibras cardíacas gerando uma resposta inibitória, além disso, esse neutransmissor controla a atenção, o aprendizado e a memória. Ela é sintetizada através da interação entre a acetilcoezimaA e a colina, ficando retida na vesícula celular e quando estimulada é liberada na fenda sináptica, que por sua vez, se liga aos receptores do neurônio seguinte para fornecer a resposta do estímulo (Guyton \& Hall, 2017).

Devido o processo de exposição aos agrotóxicos é desencadeado, na região do neurônio, uma série de reações fisiológicas, ocorrendo, principalmente, a diminuição da ação da enzima acetilcolinesterase (responsável pela quebra de excesso da acetilcolina). Logo, a exposição a agrotóxicos faz com que o neurônio continue liberando acetilcolina e assim provocando reações inibitórias e/ou excitatórias na fisiologia sistêmica do organismo (Nerilo et al., 2014). 
Conforme o autor supracitado, os agrotóxicos das classes de organofosfaratos e carbamatos são inibidores primários da acetilcolinesterase desencadeando uma série de resposta com processos sintomatológicos agudos e, se persistência na utilização química, gera sinais crônico podendo evoluir para óbito por intoxicação exógena (Nerilo et al., 2014).

Algumas classes de agrotóxicos mostram um elevado teor de riscos/danos a população exposta de forma direta e indireta. As substâncias químicas utilizadas em áreas agrícolas possuem uma alta lipossolubilidade química toxologica, ou seja, facilita a penetração em membranas biológicas, gerando absorção através das mucosas, via inalatória, tecido tegumentar e trato gastrointestinal (Marques \& Caixeta, 2016).

Os biomarcadores são identificadores dos efeitos pertinentes ao risco ocupacional da exposição a agrotóxicos, podendo ser analisados por técnicas que avaliam distintas células e moléculas biológicas, geralmente, a indicação com característica qualitativa e/ou quantitativa de níveis no processo de exposição (Pereira 2017; Ribeiro \& Mella 2007).

Além disso, a exposição crônica aos OPs pode levar ao desenvolvimento de sintomas de depressão, um fator importante nos suicídios (Korbes et al., 2010). Dessa forma, vê-se que os sinais e sintomas desenvolvidos por indivíduos expostos aos OPs estão diretamente relacionados ao grau de exposição que os indivíduos sofreram previamente.

O monitoramento das intoxicações por inibidores da colinesterase deve ser clínico e diagnóstico com a determinação da atividade colinesterásica que pode ser determinada por meio de testes específicos em sangue total, plasma ou eritrócitos (Opas,1996).

Neste mesmo contexto, Marques e Caixeta (2016, p.03) afirmam que com a inativação da enzima AchE, presentes no plasma, fígado, pâncreas e paredes do tubo digestivo, neurônios e placas motoras, resulta em elevação nos níveis do neurotransmissor acetilcolina, ocasionando estímulos excitatórios e inibitórios a depender da localização dos receptores. Portanto, a síndrome colinérgica, assim denominada, envolve principalmente o SNC, onde gera um descontrole na fisiológia dos órgãos sistêmicos. 
Quadro 1 - Ação dos Biomarcadores Endócrinos.

\begin{tabular}{|c|c|}
\hline HORMÔNIOS & LOCAL/AÇÃO \\
\hline Hormônios liberador de tirotrofina (TSH) & $\begin{array}{l}\text { Induz a maior ou menor atividade da tireoide.,O TSH é liberado } \\
\text { pela adenoipófise e age nas células produtoras dos hormônios } \\
\text { tireoidianos, tiroxina (T4)e triiodotironina (T3). }\end{array}$ \\
\hline Somatostatina & $\begin{array}{l}\text { Produzido pelas células delta do pâncreas, em lugares denominados } \\
\text { Ilhotas de Langerhans (Fator inibitório do hormônio de } \\
\text { crescimento). }\end{array}$ \\
\hline Hormônio Adrenocortrófico (ACTH) & $\begin{array}{l}\text { Atua sobre as células da camada cortical da glândula adrenal, } \\
\text { estimulando-as a sintetizar e liberar seus hormônios. Engloba } \\
\text { aldosterona, } \\
\text { cortisol e andrógenos. }\end{array}$ \\
\hline Prolactina & $\begin{array}{l}\text { Estimula a produção de leite pelas glândulas mamárias e o aumento } \\
\text { das mamas, no gênero } \\
\text { Masculino, pode gerar genicomastia e perda do libido. }\end{array}$ \\
\hline Hormônio luteinizante & $\begin{array}{l}\text { Estimula o desenvolvimento e a questão sexual em ambos os } \\
\text { gêneros. }\end{array}$ \\
\hline Vasopressina & $\begin{array}{l}\text { Atua no processo de desidratação e queda da } \\
\text { pressão arterial; Ação nos rins. }\end{array}$ \\
\hline Ocitocina & $\begin{array}{l}\text { Promove as contrações musculares uterinas; reduzir o sangramento } \\
\text { duranteo parto; } \\
\text { Estimular a libertação do leite materno; desenvolve empatia entre } \\
\text { seres. }\end{array}$ \\
\hline Gastrina & $\begin{array}{l}\text { Estimula a secreção de ácido clorídrico e } \\
\text { motilidade do estômago. }\end{array}$ \\
\hline Insulina & $\begin{array}{l}\text { Atua no pâncreas, promove a entrada da glicose em excesso do } \\
\text { sangue para as células. }\end{array}$ \\
\hline Glucagon & $\begin{array}{l}\text { Atua no pâncreas, promove o inverso do } \\
\text { hormônio insulina. }\end{array}$ \\
\hline
\end{tabular}

Fonte: Autores, adaptado pela literatura (Gayton \& Hall, 2017 p.579).

Para Gayton e Hall (2017, p.579), ilustrado no Quadro 1 acima, revelam as ações de neurotransmissores em especial os colínicos, pois são de classe I de ação imediata, caracterizando quea nível hormonal, agem no liberador de tirotrofina e hormônio luteinizante. Nessa ação hormonal pode ocorrer uma alteração celular na próstata, diferenciando os níveis do parâmetro do Antígeno Prostatário Humano (PSA). Além disso, a ação colinérgica estimula os hormônios peptídicos hipofisários adrenocorticortróficos (ACTH) que,por sua vez, envolvem as células da próstata, albumina, cortisol, hormônio luteinizantes e aldosterona.

O quadro clínico agudo gerado pela intoxicação por carbamatos e os organosfosforados (OPs) são relativamente de fácil identificação, com a manifestação clássica de um quadro colinérgico. Porém, o quadro clínico dos efeitos tardios da exposição aos OPs é em geral bastante difícil de ser identificado, podendo as consequências de uma exposição aguda serem percebidas após anos de exposição (Soares, Almeida \& Moro 2003; Ribeiro \& Mella, 2007).

A enzima colinesterase é classificada em dois tipos: acetilcolinesterase e pseudocolinesterase. A primeira, também denominada de colinesterase verdadeira ou colinesterase eritrocitária, é produzida nas hemácias, tecidos nervosos e músculos estriados; possui uma meia-vida de cerca de três meses, desempenhando maior papel na clivagem da acetilcolina nas fendas sinápticas (Câmara et al., 2012). 
A avaliação da dosagem das colinesterases AChE e BuChE determina mostrar o tipo de intoxicação aguda ou crônica, de acordo com a variação da meia vida de cada enzima. A atividade da colinesterases AChE poderá permanecer diminuída até noventa dias após o último contato com um inibidor da colinesterase porque apresenta uma menor taxa de renovação sanguínea (Ribeiro \& Mella, 2007). Já a pseudocolinesterase, também chamada de butirilcolinesterase, é inespecífica e está presente em vários sítios, como fígado, plasma, pâncreas, intestino delgado e em menor concentração no SNC e SNP, possuindo uma meia-vida mais curta, de uma semana (Câmara et al., 2012). Assim, permanecerá alterada por menos tempo após exposição a inseticidas inibidores da colinesterase por apresentar uma renovação sanguínea mais rápida devido à reposição hepática (Ribeiro \& Mella, 2007).

Essa notável diferença de tempo de meia-vida das enzimas, permite se fazer a identificação de intoxicações por inseticidas carbamatos ou organofosforados de natureza crônicas ou agudas, se configurando, portanto, a pseudocolinesterase plasmática como um biomarcador de exposição aguda e a acetilcolinesterase eritrocitária um biomarcador de efeito a esses inseticidas (Câmara et al., 2012).

Porém, deve-se manter em mente que ao menos que uma quantidade substancial de carbamato tenha sido absorvida e que a coleta de sangue tenha sido realizada dentro de uma a duas horas após a exposição, é improvável que as atividades da AChE estejam em depressão, porém um teste rápido para detectar os níveis da enzima deve ser usado como alternativa, uma vez que ocorre reativação enzimática in vivo e in vitro. Esta reativação enzimática dará resultados falso-negativos, com valores normais ou bem próximos a este, o que pode dificultar o diagnóstico em situações agudas quando não houver histórico de exposição (Roberts \& Reigart, 2013).

Portanto, a avaliação da atividade da AChE verdadeira tem maior valor na identificação de intoxicações de caráter não recente ou, mais provavelmente, de exposições sucessivas a doses mais baixas, enquanto que a dosagem da BuChE tem aplicabilidade no acompanhamento da reversão de episódios de intoxicação ou intoxicação aguda. Pode-se destacar que métodos, como o de Elman et al., por congelamento do sangue, permite a realização do monitoramento em áreas ou zonas rurais com eficácia (Ribeiro \& Mella, 2007).

Dessa forma, vê-se que provavelmente há uma subestimação dos impactos negativos na saúde da população pelo uso excessivo e inadequado dos agrotóxicos no Brasil, uma vez que os dados oficiais do Brasil são fragmentados, desarticulados e dispersos em várias fontes de informação (Brasil, 2006), dificultando a tomada de decisões e promoção de ações de prevenção e conscientização.

\section{Considerações Finais}

A presente pesquisa demonstra que o monitoramento de biomarcadores de exposição a agrotóxicos pode ser útil para verificar o surgimento de disfunções fisiológicas nas populações expostas. Ressalta-se que os biomarcadores mais utilizados para a avaliação dos trabalhadores expostos aos agrotóxicos seriam as enzimas acetilcolinesterase eritrocitária (AChE) e butirilcolinesterase (BuChE).

Atualmente, configura-se de grande importância a monitorização periódica das condições de exposição a agrotóxicos de populações de risco. Porém, conforme revisão narrativa, diversos são os desafios enfrentados pelos órgãos competentes: grande número de substâncias registradas e autorizadas no país, contrabando de ativos ilegais, falta de registro sistemático de atividades pelos trabalhadores rurais (como dose, frequência, tempo de exposição e épocas de aplicação dos agrotóxicos), utilização de misturas de ativos, dificuldades na identificação de exposições crônicas (sinais e sintomas inespecíficos) e subnotificações no Sistema de Informação de Agravos de Notificação (SINAN) pelos profissionais da Saúde. Assim, são 
necessárias mais publicações de cunho laboratorial para alertar os gestores da saúde, os trabalhadores rurais e a população em geral, sobre o perigo do uso indevido de agroquímicos.

Destarte, é de extrema importância o conhecimento acerca das classificações químicas, características físicoquímicas e toxicidade dos agrotóxicos para que haja o correto diagnóstico e manejo dos pacientes intoxicados por agrotóxicos. Também, a realização de educação continuada para as pessoas mais susceptíveis as intoxicações seria fundamental para diminuição dos casos. Além disso, o incentivo a estudos que abordem o tema deve ser instigado, uma vez que, a maioria dos casos de intoxicação por agrotóxicos não são notificados.

\section{Referências}

Almeida, V. E. S., Friedrich, K., Tygel, A. F., Melgarejo, L., \& Carneiro, F. F. (2017). Uso de sementes geneticamente modificadas e agrotóxicos no Brasil: cultivando perigos. Ciência \& Saúde Coletiva, 22(10), 3333-3339.

Alves, E. B., Casarin, N. F. B., \& Omoto, C. (2018). Lethal and sublethal effects of pesticides used in Brazilian citrus groves on Panonychus citri (Acari: Tetranychidae). Arq. Inst. Biol., 85, 1-8, e0622016.

Araujo, R. L. M., Serigati, F. C., Roque, P. (2015). Brazilian agribusiness overview. FGV Projetos.

Braga, A. R. C., de Rosso, V. V., Harayashiki, C. A. Y., Jimenez, P. C., Castro, Í. B. (2020). Global health risks from pesticide use in Brazil. Nature Food, $1(6), 312-314$.

Brasil. Ministério da Saúde. (2006). Secretaria de Atenção à Saúde. Protocolo de Atenção à Saúde dos Trabalhadores Expostos a agrotóxicos. Brasília, DF: Ministério da Saúde, 2006.

Boccolini, P., Boccolini, C. S., de Rezende Chrisman, J., Markowitz, S. B., Koifman, S., Koifman, R. J., \& Meyer, A. (2013). Pesticide use and nonHodgkin's lymphoma mortality in Brazil. International journal of hygiene and environmental health, 216(4), $461-466$.

Bochner, R. (2015). Óbito ocupacional por exposição a agrotóxicos utilizado como evento sentinela: quando pouco significa muito. Vigil. sanit. debate 3(4):39-49.

Câmara, S. A. V., Silva, I. S., Pontes, E. R. J. C., \& Barbosa, A. M. J. (2012). Exposição a agrotóxicos: determinação dos valores de referência para colinesterase plasmática e eritrocitária. Brasília Med, 2(49), 163-169.

Correia, F. S. A. Biomarcadores Salivares No Diagnóstico De Câncer Oral. (2018). Id On Line Revista de Psicologia, 12(40), 20-20, 10 mar. Lepidus Tecnologia.

Costa, V. I. D. B. D., Mello, M. S. D. C. D., \& Friedrich, K. (2017). Exposição ambiental e ocupacional a agrotóxicos e o linfoma não Hodgkin. Saúde em Debate, 41, 49-62.

Da Silva, A. C., Camponogara, S., Viero, C. M., Menegat, R. P., Dias, G. L., \& Miorin, J. D. (2016). Perfil socioeconômico de Trabalhadores Rurais portadores de neoplasia Socioeconomic profile of Rural

Workers cancer sufferers. Revista de Pesquisa: Cuidado é Fundamental Online, 8(3), 4891-4897.

Da Silva, F. R., Da Silva, J., Nunes, E., Benedetti, D., Kahl, V., Rohr, P., \& Kvitko, K. (2012). Application of the buccal micronucleus cytome assay and analysis of PON1Gln192Arg and CYP2A6*9 (-48T> G) polymorphisms in tobacco farmers. Environmental and molecular mutagenesis, 53(7), 525-534.

Faria, N. M. X et al. (2007). Intoxicação por agrotóxicos no Brasil: os sistemas oficiais de informação e desafios para realização de estudos epidemiológicos. Ciência \& Saúde Coletiva, 12(1), 25-38.

Fortes, C., Mastroeni, S., Segatto, M. M., Hohmann, C., Miligi, L., Bakos, L., \& Bonamigo, R. (2016). Occupational exposure to pesticides with occupational sun exposure increases the risk for cutaneous melanoma. Journal of occupational and environmental medicine, $58(4), 370-375$.

Gil, A. C. (2012). Como elaborar projetos de pesquisa. (6a ed.), Atlas.

Guyton, A. C., \& Hall, J. E. (2017). Tratado de Fisiologia Médica. (13a ed.), Elsevier. 1176 p.

Horn, R. C., Magni, M. P., Mori, N. C., Junges, L., Golle, D. P., Koefender, J., Manfio, C. E., Gelatti, G. T., \& Felippin, T. (2016). Avaliação “in vitro” do efeito da infusão de Cunila microcephala Benth sobre a atividade da enzima acetilcolinesterase e biomarcadores de estresse oxidativo em eritrócitos de agricultores. Rev. Bras. Pl. Med., Campinas, 18(1), 341-348.

Köche, J. C. (2004). Fundamentos de Metodologia Cientifica: Teoria da Ciência e Iniciação à pesquisa. (22a ed.).

Korbes, D., Da Silveira, A. F., Hyppolito, M. A., Munaro, G. (2010). Alterações no sistema vestibulococlear decorrentes da ex posição ao agrotóxico: revisão de literatura. Rev Soc Bras Fonoaudiol, 15(1), 146-1152.

Linhares, A. G. (2014). Efeito de pesticidas organofosforados e carbamatos sobre a acetilcolinesterase eritrocitária humana e seu potencial uso como biomarcador da exposição ocupacional. Dissertação (mestrado) - Universidade Federal de Pernambuco. Pósgraduação em Ciências Biológicas. 
Paraná. J. C. C. Secretaria Estadual de Saúde (org.). (2018). Material Técnico Intoxicações Agudas Por Agrotóxicos: atendimento inicial do paciente intoxicado. https://www.saude.pr.gov.br/sites/default/arquivos_restritos/files/documento/2020-04/intoxicacoesagu.

Marques, P. V., \& Caixeta, B. T. (2016). A Importância da Avaliação das Dosagens das Colinesterases em Casos de Intoxicações Por Organofosforados. Psicologia e Saúde em Debate. 2(1).

Marconi, M. A; Lakatos, E. M. (2014). Metodologia Científica. (7a ed.), Atlas.

Melo J. B., \& Gonçalves, S. J. C. Fatores que predispõem a intoxicação por agrotóxicos no município de Paty do Alferes. Rev Pro-univerSUS. $2014 ; 5(2): 5-35$.

Miranda Filho, A. L., Koifman, R. J., Koifman, S., \& Monteiro, G. T. R. (2014). Brain cancer mortality in an agricultural and a metropolitan region of Rio de Janeiro, Brazil: a population- based, age-period-cohort study, 1996-2010. BMC cancer, 14(1), 320.

Murussi, C., Horni, R. C., Santi, A., Claseni, B. S., Reis, G., Souza, D., Bortolotto, J. W., Manfi, C. E., \& Loro, V. L. (2014). Changes in oxidative markers, endogenous antioxidants and activity of the enzyme acetylcholinesterase in farmers exposed to agricultural pesticides - a pilot study. Ciência Rural, Santa Maria, 44(7), 1186-1193.

Nerilo, S. B., et al. (2014). Pesticide use and cholinesterase inhibition in small-scale agricultural workers in southern Brazil. Brazilian Journal Of Pharmaceutical Sciences, 50(4), 783-791.

Opas - Organização Pan-Americana da Saúde. (1996). Manual de vigilância da saúde de populações expostas a agrotóxicos. Brasília <http://www.opas.org.br/sistema/arquivos/livro2.pdf>.

Pereira, C. H. J. (2017). Avaliação Da Instabilidade Genômica e do Estresse Oxidativo em Agricultores Expostos a Agrotóxicos em um Municípo do Estado de Santa Catarina. Dissertação de mestrado (Programa de Pós-Graduação em Farmácia da Universidade Federal de Santa Catarina). Florianópolis.

Queiroz, P. R., Lima, K. C., Oliveira, T. C., Santos, M. M., Jacob, J. F., Oliveira, A. M. B. (2019). Sistema de Informação de Agravos de Notificação e as intoxicações humanas por agrotóxicos no Brasil. Rev Bras Epidemiol; 22: E190033.

Ribeiro, A. C. C., \& Mella, E. A. C. (2007). Intoxicação Ocupacional por Organofosforados - A Importância da dosagem de colinesterase. Iniciação Científica CESUMAR. 9(2), 125-134.

Roberts, J. R., \& Reigart, J. R. (2013). Recognition and Management of pesticide poisoning. 6. ed. Washington: Environmental Protection Agency, 2013.

Santana, M. R. R., Gomez, C. F., Venegas, L. Z., Sandoval, R; Roeleveld, N., Velden, K. V. D., Scheepers, P. T. J., \& Pancetti, F. (2018). Biomonitoring of blood cholinesterases and acylpeptide hydrolase activities in rural inhabitants exposed to pesticides in the Coquimbo Region of Chile. PLoS ONE $13(5)$.

Segatto, M. M., Bonamigo, R. R., Hohmann, C. B., Müller, K. R., Bakos, L., Mastroeni, S., \& Fortes, C. (2015). Residential and occupational exposure to pesticides may increase risk for cutaneous melanoma: a case-control study conducted in the south of Brazil. International journal of dermatology, 54(12), e527-e538.

Soares, W., Almeida, R. M. V. R., \& Moro, S. (2003). Trabalho rural e fatores de risco associados ao regime de uso de agrotóxicos em Minas Gerais, Brasil. Cad. Saúde Pública. 19(4), 1117-1127.

Taveira, B. L. S., \& Albuquerque, G. S. C. (2018). Análise das notificações de intoxicações agudas, por agrotóxicos, em 38 municípios do estado do Paraná. Saúde em Debate, Rio de Janeiro, 42(4), 211-222.

Vasconcelos, Y. (2018). Agrotóxicos na berlinda. Pesquisa FAPESP, 271, 18-27.

Wilhelm, C. M., Calsing, A. K., \& Da Silva, L. B. (2015). Assessment of DNA damage in floriculturists in southern Brazil. Environmental Science and Pollution Research, 22(11), 8182- 8189. 